\title{
Numerical and physical modeling of water flow over the ogee weir of the new Niedów barrage
}

\author{
Oscar Herrera-Granados ${ }^{*}$, Stanisław W. Kostecki \\ Faculty of Civil Engineering, Wrocław University of Technology, Wybrzeże Wyspiańskiego 27, Wroclaw 50-370, Poland. \\ *Corresponding author. Tel.: +48 71320 2953. E-mail: Oscar.Herrera-Granados@pwr.edu.pl
}

\begin{abstract}
In this paper, two- and three-dimensional numerical modeling is applied in order to simulate water flow behavior over the new Niedów barrage in South Poland. The draining capacity of one of the flood alleviation structures (ogee weir) for exploitation and catastrophic conditions was estimated. In addition, the output of the numerical models is compared with experimental data. The experiments demonstrated that the draining capacity of the barrage alleviation scheme is sufficiently designed for catastrophic scenarios if water is flowing under steady flow conditions. Nevertheless, the new cofferdam, which is part of the temporal reconstruction works, is affecting the draining capacity of the whole low-head barrage project.
\end{abstract}

Keywords: Hydraulic similarity; Ogee weir; Discharge coefficient; Physical modeling; 2D and 3D numerical modeling; Cofferdam.

\section{INTRODUCTION}

It is a matter of fact that climate change is causing more frequent extreme weather conditions on a global scale. Due to this climate change, unusually high rainfalls can be expected, which are far more extreme than in past decades. This situation causes severe flood events which are jeopardizing the safety of existing water bodies, reservoirs and hydraulic structures. That is the reason why water stakeholders should analyze the condition of the existing hydro-engineering projects in terms of the occurrence of new flood events, much larger than those expected at the moment of performing the original design.

The hydraulic characteristics of water flow over an ogee weir have been widely studied in the laboratory. The results presented by institutions such as the U.S. Bureau of Reclamation (USBR, 1995) and the U.S. Army Corps of Engineers (USACE, 1987) are the basis for the design of these structures. The discharge coefficient is the key parameter in order to accurately calculate the capacity of the spillway. This coefficient depends on the geometry of the spillway and on the tailwater elevation. Tullis and Neilson (2008) and Tullis (2011) performed experimental tests of nine different geometries of an ogee weir under submerged conditions. They noticed that the submerged discharge coefficients presented by the USBR are considerably overestimated for relatively high submergence ratios. Ansar and Chen (2009) presented generalized flow rating equations for different types of gated spillways which were developed based on field measurements and using dimensional analysis. The proposed ratings agreed with field measurements.

On site measurements and physical modeling are usually expensive and time-consuming. Hence, the usage of numerical simulations is becoming a popular way to obtain the hydraulic characteristics of spillways. Numerical modeling is especially useful when the classic formulas cannot be applied, such as in the case of complex geometries. Bhajantri et al. (2006) analyzed the hydraulic behavior of flow over a spillway using the finite volume method in two dimensions. They compared their results with those obtained from physical modeling and found both results to be in agreement. Salazar et al. (2013) tested the hydraulic performance of a radial-gated spillway numerically and concluded that the calculations based on empirical formulas were a match. Kirkgoz et al. (2009) tested a round crested spillway using the finite element method and the standard $k-\varepsilon$ and $k-\omega$ turbulence models. The results of their numerical calculations satisfactorily agreed with experimental data. Andersson et al. (2013) performed full 3D modeling of water spilling from the reservoir with relatively complex geometry using the volume of fluid method and compared these results with two different turbulence models, namely the standard $k-\varepsilon$ and the SSG model. The results were compared with laboratory experiments. The results reached a good quantitative agreement.

In this contribution, the authors present the methodology to compute the discharge coefficient of a classical ogee spillway using numerical and physical modeling. The application of this methodology to the Niedów barrage is described. The results of both methodologies were compared and showed a positive agreement. In addition, in order to reach hydraulic similarity between the reservoir and the model at the laboratory, the output of the 2D numerical modeling was applied to propose corrections to the physical model.

\section{STUDY SITE}

The Niedów dam is located in Poland, 1.5 kilometers east of the German border and 3.5 kilometers to the north of the border with the Czech Republic. The reservoir has an extension of almost 3 kilometers in length, with a maximum cross-section of around 900 meters. The reservoir was built between 1959 and 1968 at the chainage $2+800 \mathrm{~km}$ of Witka River (this chainage is measured from the point of discharge into the Nysa River), near the town of Niedów. This case study is of vital importance mainly due to the fact that the water body involved is located within a transnational basin according to the EU Water Framework Directive (Germany-Poland-Czech Republic). The reservoir is the water source for cooling the Turow plant and this is its main purpose. The low-head barrage structure consisted of two lateral earth dikes to elevate the headwater, as well as a three-span ogee weir with tainter gates. The two earth composite dikes had an overall height of $11.6 \mathrm{~m}$, a top width of $5.0 \mathrm{~m}$, an upstream slope of $1: 3$ covered by concrete slabs and 
a downstream slope of 1:2.5 covered by grass. The left dike had a length of around $100.0 \mathrm{~m}$ and the right dike was approximately $115.0 \mathrm{~m}$ long.

On August $7^{\text {th }}, 2010$, after a sudden and extremely high rainfall in the region of Niedów, Radomierzyce and Bogatynia, the reservoir exceeded its capacity of 5.6 million $\mathrm{m}^{3}$, causing both earth dikes to fail due the water overflow (Kostecki and Redowicz, 2014). This situation provoked the destruction of both lateral earth dikes of this low-head barrage. The flood discharge of the year 2010 was three times larger than the highest recorded flood on the Witka River. After the catastrophe, the local authorities immediately ordered the reconstruction of the hydraulic scheme. The solution proposed for the modernization consists of substituting part of the right dike with a labyrinth weir and replacing the rest of the previous earth fill dike with a concrete buttress wall. This solution was chosen because labyrinth weirs are well suited to sites where increasing the spillway width and maximum reservoir water surface elevation is difficult but larger discharges are needed (Khode and Tembhurkar, 2010). Concrete dams are also generally perceived to be more resistant to overtopping failure.

As the first phase of these reconstruction works, two cofferdams were built in order to create a temporary lower reservoir. The scheme of this short-term solution is depicted in Fig. 1a; the cofferdam cross-section is depicted in Fig. 1b and the longitudinal weir profile in Fig. 1c. The normal operation elevation before the catastrophe was 210.0 meters above sea level ( $\mathrm{m}$ a.s.1.). For the temporary solution, with the two cofferdams, the operational elevation of the reservoir was reduced to $207.0 \mathrm{~m}$ a.s.l. (Redowicz and Szulgan, 2012). After the construction of the new labyrinth concrete spillway, the normal operational level will be reverted to. Nonetheless, due to the fact that there is no plan to demolish the cofferdams, one can predict that these hydraulic structures will affect the hydraulic behavior and the draining capacity of the ogee weir. Therefore, hydraulic modeling had to be performed.

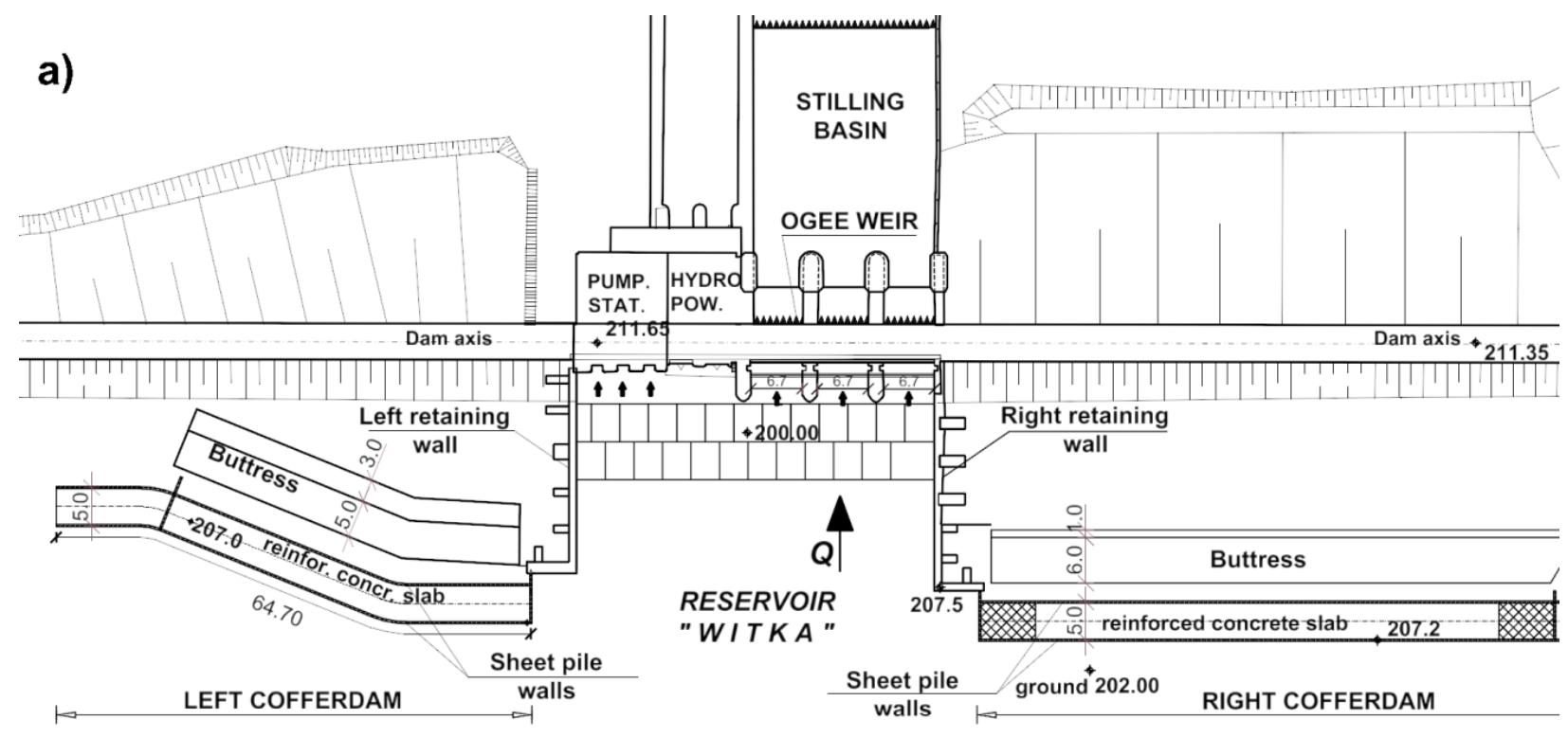

b)

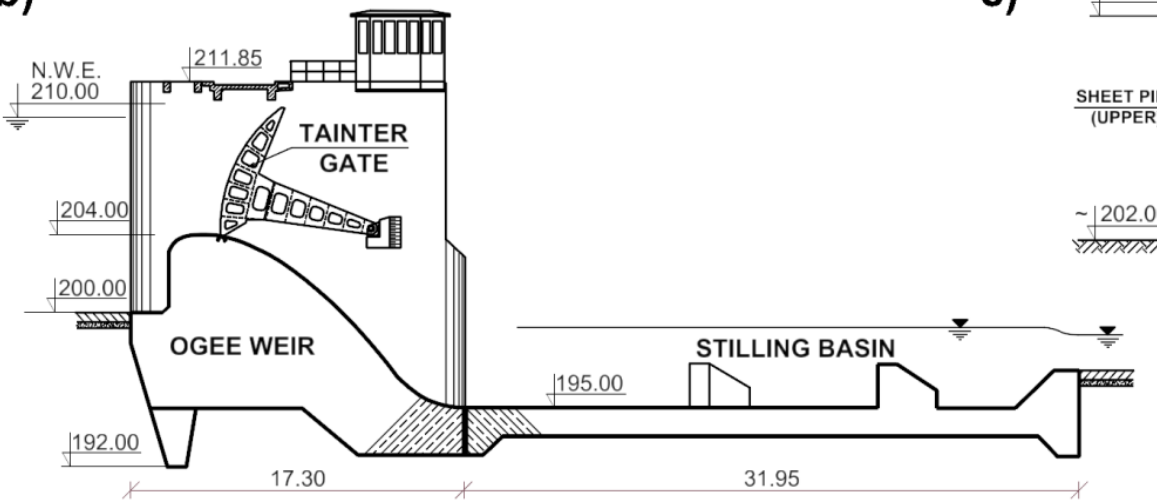

COFFERDAM

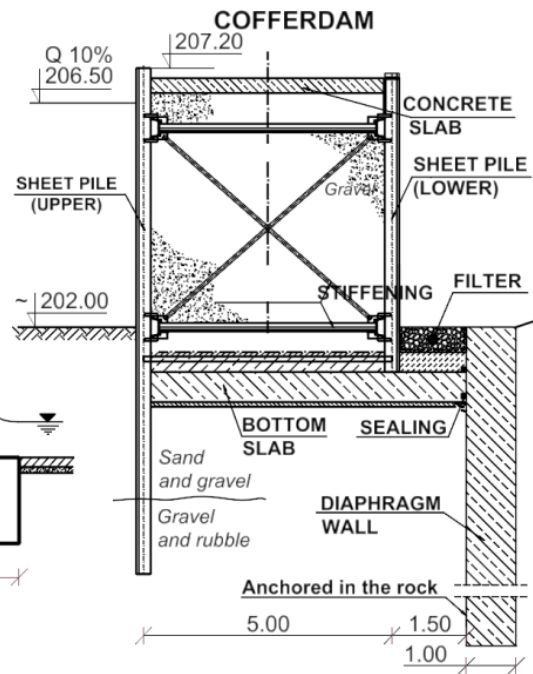

Fig. 1. a) Aerial view of the short-term proposal; b) longitudinal profile of the ogee weir with its main elements and c) cross section of the cofferdams. 


\section{HYDRAULIC MODELING}

The construction of the cofferdams resulted in changing the hydraulic behavior of water flowing over the ogee spillway. This situation was investigated using a physical model and performing numerical simulations. During the first stage, a twodimensional numerical model of water flow through the reservoir was set-up and run to determine the depth-averaged velocity distribution in the reservoir. The obtained velocity field from this model was used as boundary condition for the threedimensional model. Due to the fact that performing a threedimensional model of the whole reservoir with the required accuracy would prove difficult, costly and time-consuming, the 3D model included only a small part of the reservoir and the spillway. In addition, a physical model was built. Due to space constraints in the laboratory, this model did not cover the entire reservoir. The authors modeled only the part of the reservoir where the hydraulic scheme was reproduced. Additionally, the output of the 2D numerical simulations was used to reproduce the real inflow conditions from the reservoir to the hydraulic structure.

\section{D numerical model}

A 2D model was carried out in order to simulate the flow patterns within the reservoir and to establish the boundary conditions for the three dimensional model. The SMSFESWMS model was used for this purpose. The first step in setting up the 2D numerical model is the transformation of the data from a digital terrain model (DTM) of the reservoir to a numerical mesh of quadrilateral elements. This step was carried out using the paving algorithm, which is an advancing front meshing method for generating quadrilateral elements on a general three dimensional surface (Blacker and Stephenson, 1991).

The flood wave that occurred in 2010 was used to establish the boundary and initial conditions for this model. In Fig. 2, the simulated water depth and velocity vectors for the flow rate $Q_{p a}$ $=615 \mathrm{~m}^{3} \mathrm{~s}^{-1}$, which is the peak of the 2010 flood event, are depicted. The model was calibrated comparing its output to the registered values of the water elevation at the vicinity of the dam during the flood event of 2010. These elevations were obtained with automatic monitoring from the control room of the barrage. The lower boundary condition was established using the rating curve of the ogee weir. Thanks to the output of this model, it was possible to define the flow directions, water depths and flow velocities close to the hydraulic structure.

\section{Physical model}

Research on physical models is based on the theory of similarity between the model and the prototype. This theory provides guidance on the preparation of experiments, calculation of model parameters, processing of results, limitations of their validity and likely scale effects (Novak et al., 2010). Thus, hydraulic models work only with approximate geometric and dynamic similarity based on the ratio of the forces that determine the type of motion. In the case of open channels and spillways, the Froude similarity criterion is used because gravitational forces play a dominant role. In order to obtain proper dynamic similarity, it is also important to achieve high Reynolds numbers in the laboratory. Thus, the Froude criterion may accurately model the hydrodynamic loads produced by turbulence. Furthermore, the proper selection of the roughness

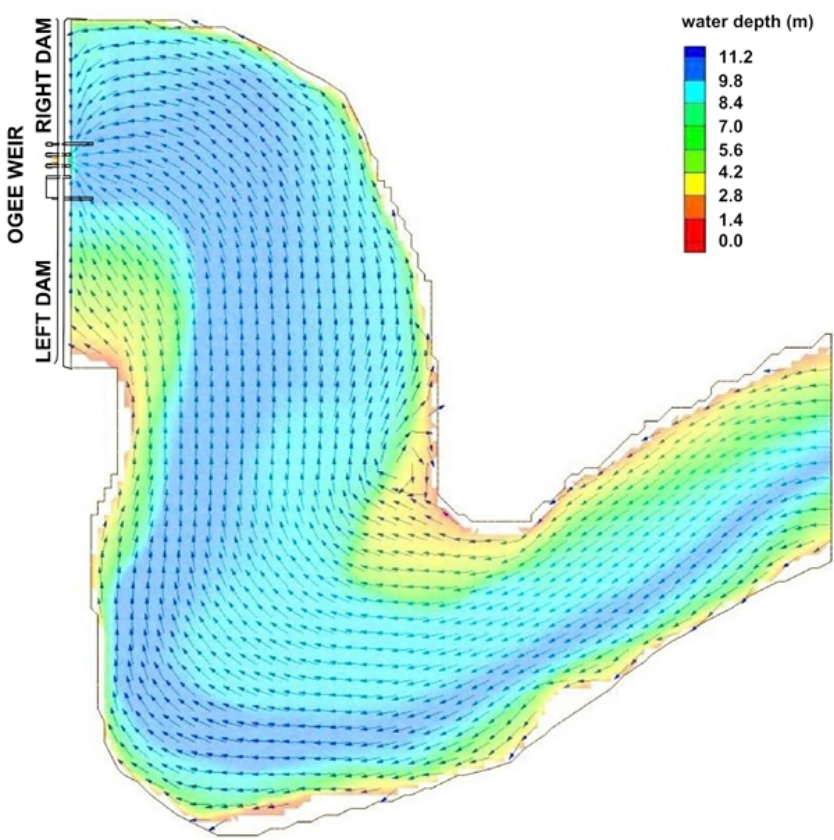

Fig. 2. Output of the 2D numerical model. Calculated water depth and depth averaged velocity vectors.

of the model materials provides an adequate representation of the hydraulic flow resistance.

The Niedów reservoir is too large to appropriately reproduce as a whole within a limited laboratory space of $400 \mathrm{~m}^{2}$. Hence, for these experimental works, about $500 \mathrm{~m}$ of the reservoir, close to the hydraulic structure, was reproduced at a length scale ratio of $\xi_{l}=27$. Fig. 3 depicts the general layout of the physical model and Fig. 4 depicts the experimental zone in which the hydraulic structure was located and the velocity time series were measured. The model of the spillway was constructed with Plexiglas and its roughness coefficient $n_{m}$ was equivalent to 0.008 compared to a roughness coefficient of concrete $n_{p}$ equal to 0.014 (Webber, 1971). This ensures that the roughness scale of $\xi_{n}=\left(\xi_{l}\right)^{1 / 6}=1.73$ is fulfilled. Indexes $m$ and $p$ represent model and prototype values, respectively. Other scales applied to the physical model are: the discharge scale ratio $\xi_{Q}=\left(\xi_{l}\right)^{5 / 2}=3788$, velocity and time scale ratio $\xi_{v, t}=\left(\xi_{l}\right)^{1 / 2}=5.20$. The Reynolds number $\left(R e_{m}\right)$ of the laboratory model was calculated using the formula (1):

$R e_{m}=\frac{v_{m} h_{m}}{v_{m}}$

where $v_{m}$ is the average water velocity; $h_{m}$ is the water depth of the model before the ogee weir and $v_{m}$ is the kinematic water viscosity. In the cross-section of the reservoir before the spillway, $R e_{m}$ was equal to $2.10 \cdot 10^{4}$ and in the outflow channel $R e_{m}$ was equal to $16.6 \cdot 10^{4}$ for the scaled peak flood flow of the year 2010 and it was large enough to ensure a dynamic similarity between the model and the prototype.

The Niedów reservoir has $S$-like shape in its final section, meaning that the streamlines and flow distribution could not be adequately replicated in the laboratory. Therefore, a correction to the physical model was proposed using the output of the 2D numerical model. Four PVC blades, acting as guiding walls, 


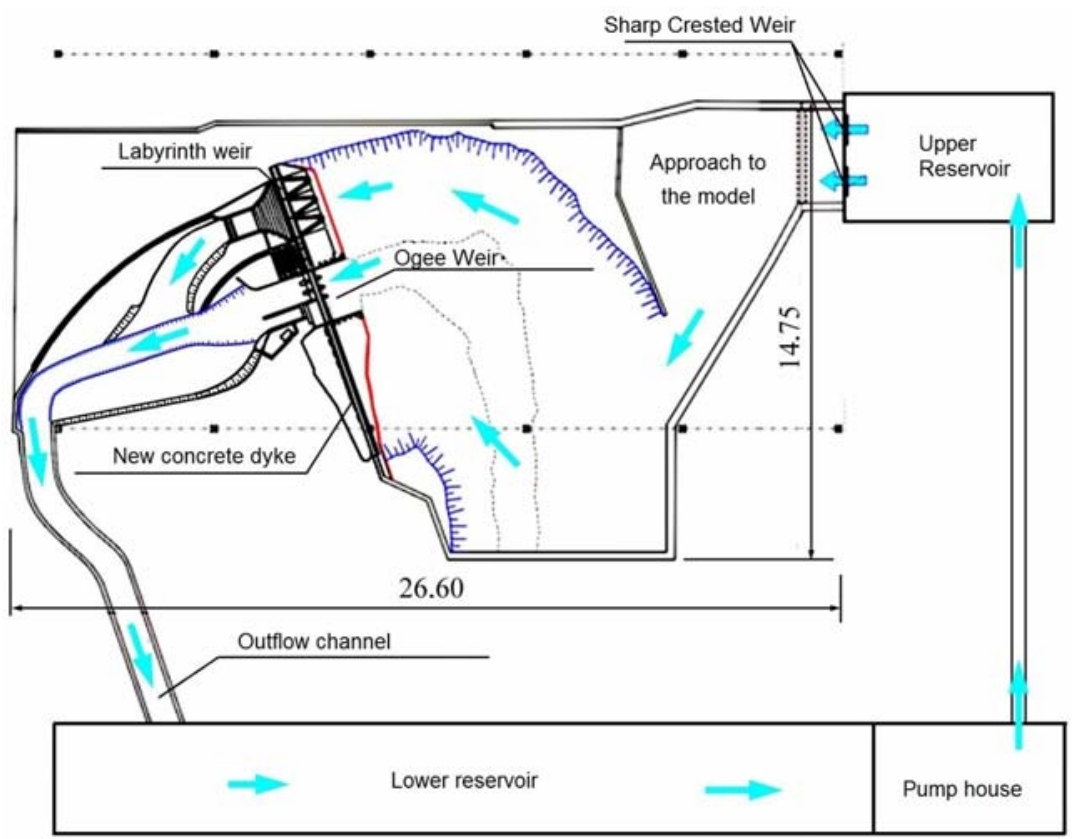

Fig. 3. Aerial view of the physical model's scheme (dimensions in meters).

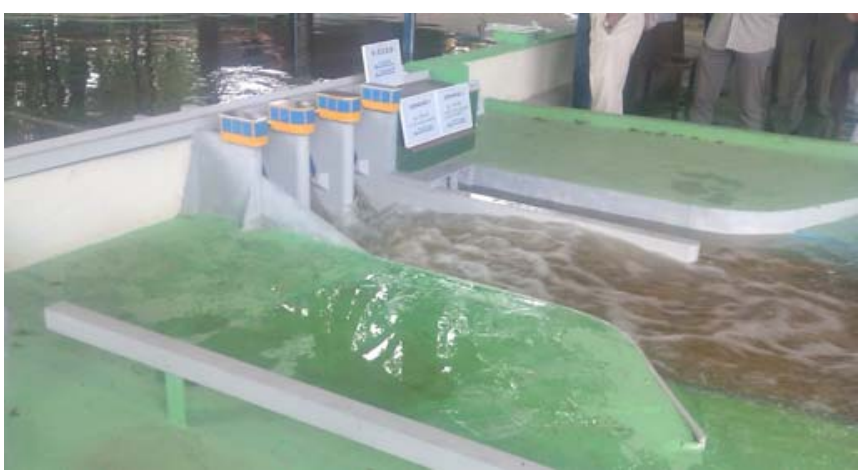

Fig. 4. Physical model: View of the concrete structure from downstream side.

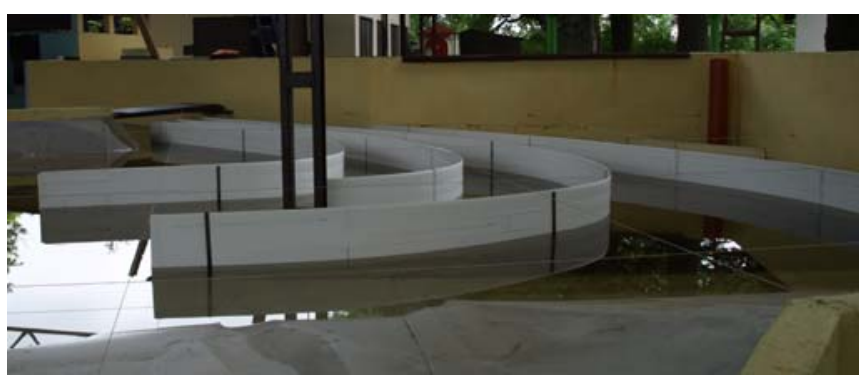

Fig. 5. PVC guiding walls: Correction applied to the physical model in order to reach hydraulic similarity of the velocity field between model and prototype.

were installed from the bottom of the physical model to an equivalent elevation of $210.5 \mathrm{~m}$ a.s.1. (see Fig. 5). The objective of these walls was to coerce the water, from the beginning of the physical model (close to the sharp crested weir) to the experimental zone, in a similar way to the process taking place in the actual reservoir. The final layout of the model with the correction is depicted in Fig. 6, together with the output of the $2 \mathrm{D}$ numerical model. In cross-sections $A-A$ and $B-B$, a mass ba-
Table 1. Mass balance to reach similarity.

\begin{tabular}{lccc}
\hline \multicolumn{4}{c}{ Cross section $A-A$} \\
\hline Id & $Q_{i}\left(\mathrm{~m}^{3} \mathrm{~s}^{-1}\right)$ & $B_{\text {res }}(\mathrm{m})$ & $Q_{i} / Q_{p a}$ \\
\hline$Q_{p 1}$ & 170 & 70 & 0.276 \\
$Q_{p 2}$ & 172 & 45 & 0.280 \\
$Q_{p 3}$ & 123 & 50 & 0.200 \\
$Q_{p 4}$ & 150 & 80 & 0.244 \\
\hline \hline \multicolumn{4}{c}{ Cross section $B-B$} \\
\hline Id & $Q_{i}\left(\mathrm{~m}^{3} \mathrm{~s}^{-1}\right)$ & $B_{m}(\mathrm{~cm})$ & $Q_{i} / Q_{m a}$ \\
\hline$Q_{m 1}$ & 48.1 & 45 & 0.297 \\
$Q_{m 2}$ & 41.3 & 45 & 0.255 \\
$Q_{m 3}$ & 32.9 & 40 & 0.203 \\
$Q_{m 4}$ & 39.7 & 57 & 0.245 \\
\hline \multicolumn{4}{r}{}
\end{tabular}

lance analysis was carried out. The results of flow measurements in the laboratory (cross section $B-B$ ) were compared with the $2 \mathrm{D}$ numerical calculations of water flowing through the Niedów reservoir (cross section $A-A$ ). The estimated real flow rates $Q_{p 1}, Q_{p 2}, Q_{p 3}$ and $Q_{p 4}$ showed results very similar to the scaled flow rates $Q_{m 1}, Q_{m 2}, Q_{m 3}$ and $Q_{m 4}$. The results of this mass balance is presented in Table 1 for the catastrophic flow condition $Q_{p a}=615 \mathrm{~m}^{3} \mathrm{~s}^{-1}$.

Once the mass balance was carried out, the validation of the physical model was performed comparing the water elevation between the model and the prototype. The water level upstream of the hydraulic structure was measured manually with a point gauge at the distance of $5 H$ from the spillway crest, where $H$ is the overflow head over the ogee weir. This gauge has an accuracy of $0.1 \mathrm{~mm}$. The measurements included 22 discharges from 75 to $615 \mathrm{~m}^{3} \mathrm{~s}^{-1}$ for the prototype and concurred with one another. The differences in the water levels between the model and the prototype presented errors of less than $4 \%$. Once these comparisons were verified, the calculations of the discharge coefficient $C_{0}$ were carried out.

Several series of turbulent flow measurements were recorded using a Programmable Electromagnetic Liquid Velocity Meter (P-EMS), with an accuracy of $0.001 \mathrm{~m} \mathrm{~s}^{-1}$. These velocity time series were recorded along each of the three spans of the ogee spillway (S1, S2, S3), from left to right (from downstream side 


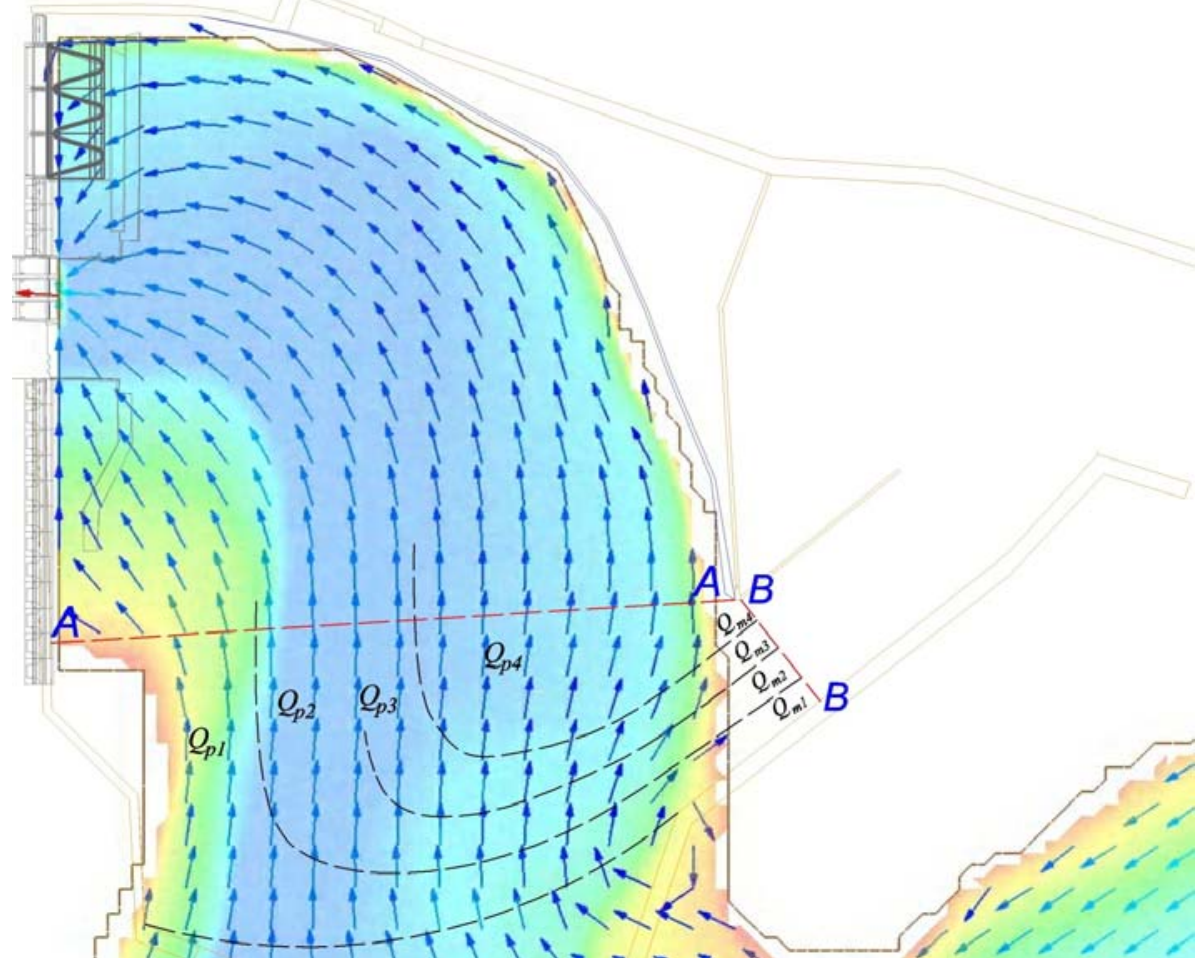

Fig. 6. Similarity verification using the output of the 2D numerical modeling.

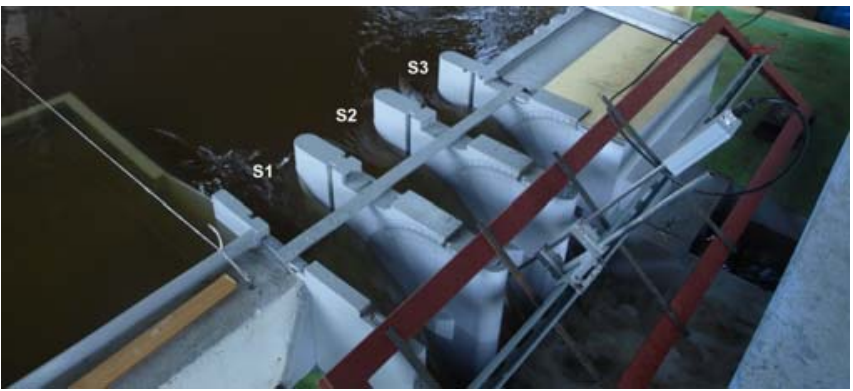

Fig. 7. View of the experimental setup to calculate $C_{0}$.

of the physical model), at a constant depth of $0.35 H_{p}$; where $H_{p}$ is the perpendicular water depth from the spillway bottom to the free surface. Fig. 7 depicts the location of the P-EMS and the three spans. The velocity profiles recorded at spans S1, S2 and $\mathrm{S} 3$ allowed the estimation of the flow distribution of each weir and the average flow rate per spillway. The flow rate values, obtained in the laboratory, for the flood wave conditions of the year $2010\left(Q_{m a}\right)$, as well as for two exploitation flow conditions $\left(Q_{m b} \& Q_{m c}\right)$, are depicted in Table 2. The values of Table 2 show that the flow distribution at each span is different above all for smaller flow conditions; this fact can be a consequence of the influence of the temporary cofferdams on the weir's draining capacity.

\section{D numerical model}

The 3D numerical model was based on commonly used Reynolds-average Navier-Stokes (RANS) equations. To solve RANS equations, a commercially available Computational Fluid Dynamics (CFD) code, Flow3D, was used. Flow3D calculates free surfaces with the Volume of Fluid (VOF) technique and also incorporates a special technique, known as the FAVOR (Fractional Area Volume Obstacle Representation)
Table 2. Measured ogee weir flow rates.

\begin{tabular}{ccccccc}
\hline Id & $\begin{array}{c}Q_{m a \_} i \\
\left(\mathrm{dm}^{3} \mathrm{~s}^{-1}\right)\end{array}$ & $\begin{array}{c}Q_{m a \_} i \\
Q_{m a}\end{array}$ & $\begin{array}{c}Q_{m b} i \\
\left(\mathrm{dm}^{3} \mathrm{~s}^{-1}\right)\end{array}$ & $\begin{array}{c}Q_{m b \_} i \\
Q_{m b}\end{array}$ & $\begin{array}{c}Q_{m c_{-i} i} \\
\left(\mathrm{dm}^{3} \mathrm{~s}^{-1}\right)\end{array}$ & $\begin{array}{c}Q_{m c_{-} i} \\
Q_{m c}\end{array}$ \\
\hline S1 & 52.1 & 0.32 & 13.1 & 0.33 & 6.2 & 0.31 \\
S2 & 57.2 & 0.35 & 14.1 & 0.35 & 7.3 & 0.36 \\
S3 & 52.7 & 0.33 & 12.8 & 0.32 & 6.5 & 0.33 \\
\hline
\end{tabular}

method (Savage and Johnson, 2001), to define general geometric regions within a rectangular grid. The water level in this 3D numerical model was calculated with this methodology. The FAVOR method view of the ogee spillway and the numerical meshes that were used for the analysis are depicted in Fig. 8a. To discretize RANS equations, the computer software uses the generalized minimum residual method.

Three numerical hexahedron meshes (two large and one nested), built with uniform cubic elements, were used in order to correctly simulate the water flow from the reservoir to the hydraulic structure (mesh 1, grid $1.0 \mathrm{~m} \mathrm{x} 1.0 \mathrm{~m} \mathrm{x} 0.2 \mathrm{~m}$ ), to calculate flow behavior over the alleviation scheme (mesh 2 , grid $1.0 \mathrm{~m} \mathrm{x} 1.0 \mathrm{~m} \times 0.2 \mathrm{~m}$ ) and to properly calculate the water flow over the spillway close to the supports of the tainter gates (mesh 3 - nested finest mesh, grid $0.2 \mathrm{~m} \times 0.2 \mathrm{~m} \mathrm{x} 0.1 \mathrm{~m}$ ). The boundary conditions of the 3D numerical are depicted in Fig. $8 \mathrm{~b}$. In the upstream side of the hydraulic structure (mesh 1), these boundary conditions were established using the simulated velocity field of the 2D numerical model (designated the letter $\mathrm{V}$ in Fig. 8b) and an outflow boundary condition for the flow rate approaching the weir (designated letter $\mathrm{O}$ ). In the downstream side (mesh 2), the real water level was established as a boundary condition (designated the letter $\mathrm{P}$, or pressure condition, in Fig. 8b). In addition, the CFD code provides the option of defining a "S - symmetry" boundary condition, which means that all fluxes into the boundary are equal to zero. This boundary type was used in meshes 2 and 3 . 

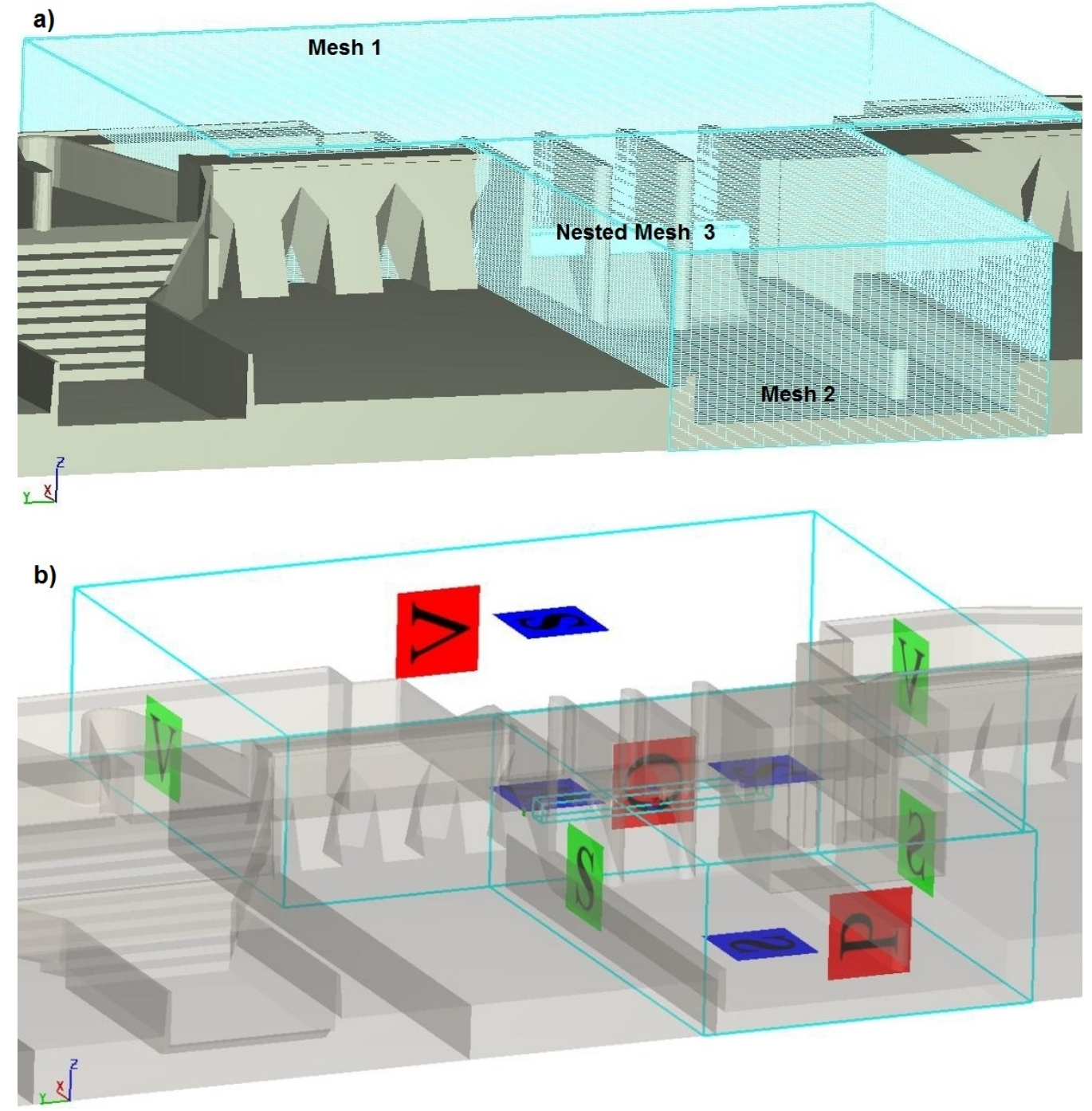

Fig. 8. a) FAVOR method view of the hydraulic structure and numerical meshes. b) Defined boundary conditions according to Flow3D notation.
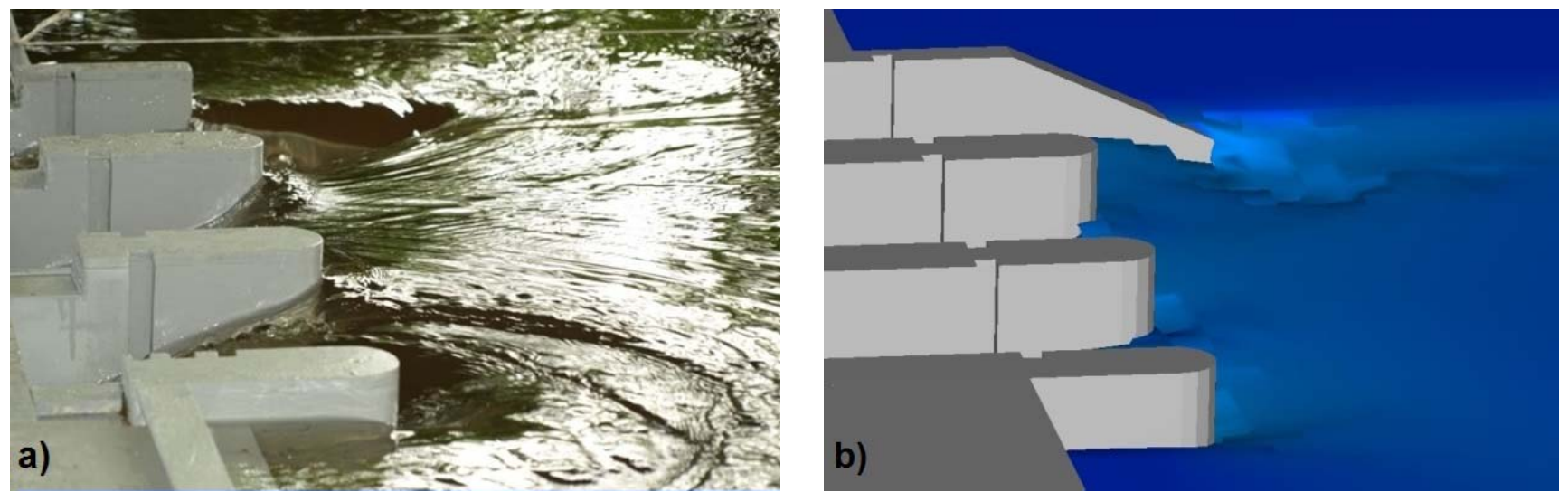

Fig. 9. a) Flow over the spillway at the laboratory and b) flow visualization over the spillway using RANS modeling.

In Figs. 9a and 9b, the water flow approaching the ogee spillway in the laboratory and with the usage of the numerical model are respectively depicted. This figure demonstrated that the CFD code is appropriately simulating the water flow over the ogee weir. The 3D numerical model was calibrated changing the roughness coefficient of the structure and comparing it to the scaled values of the velocity measurements from the laboratory. Once the model was calibrated, a new scenario was modeled: water flow through the alleviation scheme without the cofferdams. This scenario was analyzed in order to verify the influence of the structure on the draining capacity of the ogee spillway. 


\section{RESULTS OF THE MODELS}

The general equation for weir discharge is given by (USBR, 1995):

$Q=C_{0} \sqrt{2 g} L H_{e}^{3 / 2}$

where $Q$ is the total discharge; $L$ is the crest length; $H_{e}$ is the total head upstream above the weir crest; $g$ is the gravitational acceleration and $C_{0}$ is the discharge coefficient. Note that $H_{e}$ already includes the velocity head.

Using the output of the numerical and physical models, the value of $C_{0}$ (WCD - with cofferdams) is calculated for the existing condition (with the temporary cofferdams) and with the $3 \mathrm{D}$ numerical model; the theoretical value of $C_{0}$ (WOCD without cofferdams) for the same hydraulic structure but without cofferdams is calculated. This analysis was carried out for the flow that occurred in $2010 Q_{p a}=615 \mathrm{~m}^{3} \mathrm{~s}^{-1}$ and for another seven hydrological conditions, including $Q_{p b}=150 \mathrm{~m}^{3} \mathrm{~s}^{-1}$ and $Q_{p c}=75 \mathrm{~m}^{3} \mathrm{~s}^{-1}$, which correspond to the scaled flow rates $Q_{m b}$ $\& Q_{m c}$ of Table 2. The results of this analysis are presented in Table 3 and in Fig. 10. The theoretical values for designing hydraulic structures proposed by the USBR (1995) are also presented and depicted in the same table and figure. In Fig. 10, the shape of the curve that represents the values of $C_{0}$, based on the numerical model without the cofferdam, is similar to the shape of the curve of the values proposed by the USBR. The results of $C_{0}$ with the cofferdam obtained from the experiments and from the numerical model are in agreement. Based on the results of the presented study, the discharge capacity of the ogee weir is reduced by the existence of the cofferdams. For operational flows, there is a difference in the discharge coefficient

Table 3. Comparison of the discharge coefficients.

\begin{tabular}{ccccc}
\hline \multicolumn{5}{c}{ Comparison of results } \\
\hline $\begin{array}{c}Q \\
\left(\mathrm{~m}^{3} \mathrm{~s}^{-1}\right)\end{array}$ & $\begin{array}{c}C_{0} \\
(\mathrm{lab})\end{array}$ & $\begin{array}{c}C_{0} \\
(\mathrm{WCD})\end{array}$ & $\begin{array}{c}C_{0} \\
(\mathrm{WOCD})\end{array}$ & $\begin{array}{c}C_{0} \\
(\mathrm{USBR})\end{array}$ \\
\hline$Q_{p a}$ & 0.462 & 0.467 & 0.472 & 0.479 \\
$Q_{p b}$ & 0.436 & 0.435 & 0.441 & 0.435 \\
$Q_{p c}$ & 0.435 & 0.434 & 0.439 & 0.421 \\
230 & 0.437 & 0.436 & 0.445 & 0.447 \\
280 & 0.436 & 0.436 & 0.448 & 0.454 \\
340 & 0.438 & 0.438 & 0.453 & 0.461 \\
400 & 0.439 & 0.440 & 0.458 & 0.467 \\
500 & 0.445 & 0.445 & 0.465 & 0.473 \\
\hline
\end{tabular}

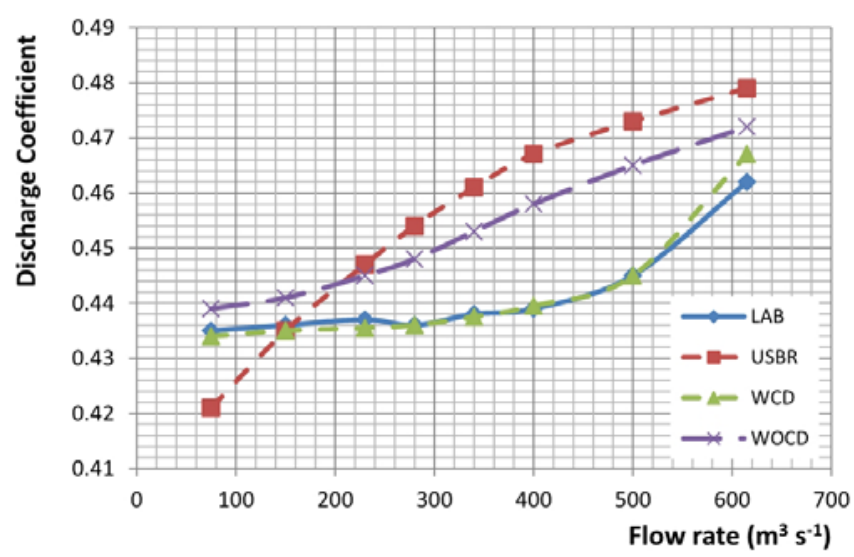

Fig. 10. Comparison of the ogee weir coefficient values. values obtained on the physical model at a range of $0.00 \%$ to $0.34 \%$ when compared to the discharge coefficients estimated with the numerical model. For the peak flood wave of the year 2010, this difference of the obtained $C_{0}$ value is around $1.05 \%$. Thus, one can state that the results of both models showed strong similarities.

\section{CONCLUSIONS}

Full three-dimensional numerical modeling was used to analyze the impact of cofferdams on the draining capacity of a spillway consisting of three ogee weirs. The cofferdams were initially intended to be short-term solutions for the new hydraulic structure at the Witka River. Nevertheless, both dikes became part of the final layout of the new structure. The numerical model included part of a reservoir with both lateral cofferdams, which were placed in front of the powerhouse, the ogee spillways and a new labyrinth weir. The boundary conditions of this model were defined on the results of an additional twodimensional model analyzing the flow through the reservoir. The combined 2D and 3D models showed a reasonable agreement with the measurements recorded on a physical model.

The comparison between the values of the discharge coefficient of the ogee spillway with and without the cofferdams showed that not removing these dikes decreased the flow capacity by around $1.14 \%$ for operational flows and $1.06 \%$ for the peak of the flood wave. Nevertheless, the discharge capacity of the weir is drastically reduced for small flood waves, within a range of 200 to $500 \mathrm{~m}^{3} \mathrm{~s}^{-1}$, when $C_{0}$ can be reduced up to $4.3 \%$. On the one hand, the comparison of the calculated discharge coefficients of the ogee weir from the 3D numerical model, with the values proposed by the USBR, showed that the latter is larger (for large flows) due to the non-uniform velocity field in the reservoir. This hydraulic behavior is probably provoked by the $S$-like shape of the reservoir. On the other hand, for small operational flows, the values estimated using the models are larger than the values proposed by the USBR. This behavior may be caused by the existence of cofferdams that retain water and create a small pool in the vicinity of the spillway.

The presented results in this contribution may encourage water specialists to analyze the functionality and draining capacity of ogee weirs using CFD. The authors are convinced that the combination of 2D-3D numerical approaches represents a feasible tool to analyze the conditions of existing hydroengineering projects that are prone to being jeopardized due to extreme rainfalls as a consequence of climate change.

\section{REFERENCES}

Andersson, A., Andreasson, P., Lundström, T., 2013. CFDmodelling and validation of free surface flow during spilling of reservoir in down-scale model. Eng. Appl. Comp. Fluid, 7, 159-167.

Ansar, M., Chen, Z., 2009. Generalized flow rating equations at prototype gated spillways. J. Hydraulic Eng., 135, 602-608.

Bhajantri, M., Eldho, T., Deolalikar, P., 2006. Hydrodynamic modelling of flow over a spillway using a two-dimensional finite volume-based numerical model. Sadhana, 31, 743754.

Blacker, T., Stephenson, M., 1991. Paving: A new approach to automated quadrilateral mesh generation. Int. J. Num. Methods Eng., 32, 811-847.

Khode, B., Tembhurkar, A., 2010. Evaluation and analysis of crest coefficient for labyrinth weir. World Appl. Sciences J., $11,835-839$. 
Kirkgoz, M., Akoz, M., Oner, A., 2009. Numerical modeling of flow over a chute spillway. J. Hydraul. Res., 47, 790-797.

Kostecki, S. W., Redowicz, W., 2014. The washout mechanism of the Niedów dam and its impact on the parameters of the flood wave. Proc. Eng., 91, 292-297.

Novak, P., Guinot, V., Jeffrey, A., Reeve, D., 2010. Hydraulic Modelling - an Introduction. Principles, Methods and Applications. Spon Press, London and New York.

Redowicz, W., Szulgan, R., 2012. Temporal retention reservoir at the river Witka in Niedów Przeg. Budowlany, 5, 88-91. (In Polish.)

Salazar, F., Moran, R., Rossi, R., Onate, E., 2013. Analysis of the discharge capacity of radial-gated spillways using CFD and ANN - Oliana dam case study. J. Hydraulic Res., 51, 244-252.

Savage, B.M., Johnson, M.C., 2001. Flow over ogee spillway: Physical and numerical model case study. J. Hydraulic Eng., $128,640-649$.
Tullis, B., 2011. Behavior of submerged ogee crest weir discharge coefficients. J. Irrig. Drain. Eng., 137, 677-681.

Tullis, B., Neilson, J., 2008. Performance of submerged ogeecrest weir head-discharge relationships. J. Hydraulic Eng., 134, 486-491.

USACE, 1987. Hydraulic design of spillways, engineer manual 1110-2-1603. U.S. Army Corps of Engineers, New York.

USBR, 1995. Design of small dams. U.S. Bureau of Reclamation, Denver, CO, 1987.

Webber, N., 1971. Fluid Mechanics for Civil Engineers, Spon, London, UK.

Received 15 June 2015 Accepted 11 December 2015

Note: Colour version of Figures can be found in the web version of this article. 